\title{
Polypharmacy and the Contributing Factors Among Elderly Patients in Shashemene Referral Hospital, West Arsi, Oromia Region, Ethiopia
}

Gudeta Duga Geresu1, Tadele Mekuria Yadesa ${ }^{1 *}$ and Bontu Aschale Abebe ${ }^{2}$

${ }^{1}$ Department of Pharmacy, College of Health Science, Ambo University, Ethiopia

${ }^{2}$ Department of Midwifery, College of Health Science, Ambo University, Ethiopia

\begin{abstract}
Background: Population ageing is a result of high life expectancy and declining fertility. Medication use in older people is a particular public health concern since the older population has a higher prevalence of multiple drug use referred to as 'poly-pharmacy'. This study aimed to determine poly-pharmacy and the contributing factors among elderly patients at Shashemene Referral Hospital.
\end{abstract}

Materials and methods: A Health facility based prospective cross sectional study was conducted. Elders of 65 and above years old were enrolled. Data was analyzed by SPSS version 16.0 software. Logistic regression analysis was used to assess association of variables with poly-pharmacy. Statistical significance was conducted at p-value $<0.05$.

Results: The total number of population enrolled in the study was 116 elders ( $60 \mathrm{yrs}$ old and above). Among this, $59.5 \%$ were males. The primary diagnosis of most patients was infection $(50 \%(n=58))$ and followed by cardiovascular disorders $(18.1 \%(n=21))$. The widely used drug group was antimicrobials $(58.7 \%)$, followed by cardiovascular $(25 \%)$ and GIT drugs (13.8\%). Almost half, (48.3\%), of population were taking 1-2 drugs. The maximum total number of drug per patient was seven drugs of the same or different classes. Poly-pharmacy was observed among almost one-third $(32.75 \%)$ of study subjects with highest prevalence among younger elders (65yrs-69 yrs old). The polypharmacy that has been seen in elderly in highest prevalence was appropriate poly-pharmacy, $79 \%$. Co-morbidity $(\mathrm{AOR}=7.427)$ and occupation, employee, $(\mathrm{AOR}=8.840)$ were the contributing factors of poly-pharmacy.

Conclusion and recommendations: In this study, a total of 116 elderly patients, 69 males and 47 females, were involved. The primary diagnosis of most patients was infection. Co-morbidity has been seen in over one-third of the study subjects. The widely used drug group was antimicrobials, followed by cardiovascular. The study also shows that poly-pharmacy was prevalent in almost one third of the elderly patients in SRH. The multivariate logistic regression showed that co-morbidity and occupation, employee, were the factors independently associated with poly-pharmacy. The health care system should improve the prescribing process among elderly patients.

Keywords: Polypharmacy; Contributing factors; Elderly; Shashemene; Ethiopia

Abbreviations: ADR: Adverse Drug Reaction; CMHS: College of Medicine and Health Sciences; CNS: Central Nervous System; CVS: Cardio Vascular System; GIT: Gastro Intestinal System; MRP: Medication Related Problems; SPSS: Statistical Packages for Social Sciences; SRH: Shashemene Referral Hospital; TASH: Tikur Anbessa Specialized Hospital; WHO: World Health Organization

\section{Introduction}

Population ageing is a result of high life expectancy and declining fertility. It is now a global phenomenon as the number of older population is rapidly increasing. The number of the aged population is being projected to be around 1.5 billion in 2050 , with $80 \%$ of them in the developing countries [1]. As in most other countries, the proportion of elderly people in Ethiopia is growing rapidly [2].

Studies show that aging can alter practically all pharmacokinetic processes including: absorption, first-pass metabolism, bioavailability and distribution, protein-binding and renal and hepatic clearance. These alterations contribute to an increasing risk of adverse drug reactions. Additionally, the aging of the population and the resulting increase of multiple chronic diseases have led to multiple drug prescriptions and drug-drug interactions. Medication use in older people is a particular public health concern since the older population has a higher prevalence of multiple drug use, referred to as 'poly-pharmacy' [3].

From dictionary meaning, the term "poly-pharmacy" came from two word roots. "Poly" is derived from the Greek word meaning more than one and pharmacy referring to the Greek word for drug "pharmacon". Hence the full meaning of poly-pharmacy is using many (more than one) drugs concurrently [4]. Poly-pharmacy can be defined both quantitatively and qualitatively. There is no standard cut point with regard to the number of medications that is agreed up on for the definition of poly-pharmacy [5]. The definition of poly-pharmacy varies in the literature, but it ranges from the concurrent use of two or more to five or more prescription drugs [6]. However, it is mostly defined as the concurrent use of four or more prescription drugs $[7,8]$. There are many studies which have used minor and major poly-pharmacy. Minor poly-pharmacy refers to concurrent use of two to four prescribed medications and major poly-pharmacy as concurrent use of five or more prescribed medications [5].

*Corresponding author: Tadele Mekuria Yadesa, Lecturer and Clinical Pharmacy Specialist, Department of Pharmacy, College of Health Science, Ambo University Ambo, Ethiopia, Tel: +251471110331; E-mail: maatiikoo4@gmail.com

Received October 23, 2017; Accepted November 22, 2017; Published November 30, 2017

Citation: Geresu GD, Yadesa TM, Abebe BA (2017) Polypharmacy and the Contributing Factors Among Elderly Patients in Shashemene Referral Hospital, West Arsi, Oromia Region, Ethiopia. J Bioanal Biomed 9: 277-282. doi:10.4172/1948593X.1000193

Copyright: () 2017 Geresu GD, et al. This is an open-access article distributed under the terms of the Creative Commons Attribution License, which permits unrestricted use, distribution, and reproduction in any medium, provided the original author and source are credited. 
Generally one simple definition is based on the total number of different medications a patient takes concurrently [9]. This definition excludes topical and herbal medications as they are often not included in the traditional methods of assessing prescription quality. Vitamins and minerals taken as much needed by individuals are also generally excluded because of the inconsistent inclusion of these medications in poly-pharmacy [10]. However, these drugs, while they don't require a prescription, are just as likely to cause interactions with other over-thecounter medications as well as prescription medications [3].

Another definition for poly pharmacy is the qualitative definition of poly-pharmacy. Qualitatively, poly-pharmacy can be divided in to appropriate poly-pharmacy and inappropriate poly-pharmacy. Inappropriate poly-pharmacy is present when one or more drugs are prescribed that are not or no longer needed, either because: (a) there is no evidence based indication, the indication has expired or the dose is unnecessarily high; (b) one or more medicines fail to achieve the therapeutic objectives they are intended to achieve; (c) one or the combination of several drugs cause unacceptable adverse drug reactions (ADRs) or put the patient at an unacceptably high risk of such ADRs or because (d) the patient is not willing or able to take one or more medicines as intended. Appropriate polypharmacy is present, when: (a) all drugs are prescribed for the purpose of achieving specific therapeutic objectives that have been agreed with the patient; (b) therapeutic objectives are actually being achieved or there is a reasonable chance they will be achieved in the future; (c) drug therapy has been optimized to minimize the risk of ADRs and (d) the patient is motivated and able to take all medicines as intended [11].

Inappropriate poly-pharmacy is a particular concern in older people and is associated with negative health outcomes. Choosing the best interventions to improve appropriate poly-pharmacy is a priority; hence there is growing interest in appropriate poly-pharmacy where many medicines may be used to achieve better clinical outcomes for patients [12].

Many older adults have multiple medical conditions, such as hypertension, arthritis, heart disease, cancer and diabetes mellitus, which require multiple medications for proper treatment. Unfortunately, using multiple medications (i.e., poly-pharmacy) may cause problems such as the increased risk of inappropriate use of medications (including drug-drug interactions and duplication of therapy), non-adherence, high health care costs and adverse effects [13]. Poly-pharmacy increases the possibility of "prescribing cascades". A prescribing cascade develops when an adverse drug event is misinterpreted as a new medical condition and additional drug therapy is then prescribed to treat this medical condition [10].

As compared to young adults, elderly persons have more illness, as aging is often accompanied by chronic diseases, co-morbidities, disabilities and social isolation. Also, they are the most common group to be admitted to hospitals. Hence, it is not surprising that both the frequency of drug therapy and average number of drugs taken per person progressively increase with age. Co-morbidity leads to use of multiple drugs, a condition commonly known as poly-pharmacy [14].

In the United States, medication-related problems (MRPs) are public health threat that costs 200,000 lives and $\$ 200$ billion a year. Furthermore, half of the illness, disability and premature death caused by MRPs are preventable [15].

In Ethiopia, as of the beginning of 2017 , the total population was estimated to be $103,205,224$; of which $2,754,547(2.7 \%$ of total) were the elderly. Additionally, data from growth rate (19522017) indicates that trend in population number is increasing with increase in elderly proportion [16]. Drug-related harm among the elderly is one of the most challenging public health issues globally [12]. The study done in TASH showed that poly-pharmacy has a significant association with the occurrence of MRP [17]. However, the cause of this poly-pharmacy is from different directions. The discovery of a broad range of pharmaceuticals for a wide variety of conditions has helped many patients. Unfortunately, this new development has also led to both overuse and inappropriate use of prescription drug. In addition to availability of medications, comorbidity, non-adherence receiving care from several health care providers and prescribing cascade are causes that can lead to polypharmacy [18].

\section{Methods and Participants}

\section{Study area and study period}

The study was conducted in SRH which is found in Shashemene town, Oromia region, south west Ethiopia. It is located $238 \mathrm{~km}$ away from the capital city of Ethiopia, Addis Ababa.

The hospital has 205 beds and is providing several health services (inpatient and outpatient) for the community such as medical, pediatrics, obstetrics, gynaecology, surgery, psychiatry, ophthalmology and emergency and outpatient department activities. The study was conducted from March 23-April 21, 2017 G.C.

\section{Study design}

A health facility based prospective cross sectional study type was conducted based on demographic and medical information of elderly patients who have been attending SRH during the study period (from March 23 up to April 21, 2017). The necessary data was extracted using pretested structured data collection formats/questionnaire.

\section{Population}

Source population: All elderly patients who visit SRH during the study period.

Study population: All elderly patients who have been visiting SRH during the study period.

Study unit: Voluntary elderly patient with his/her medication card in SRH during the study period.

\section{Selection criteria}

\section{Inclusion criteria:}

- All patients greater than or equal to $65 \mathrm{yrs}$ old.

- Patients who have complete medication card.

\section{Exclusion criteria:}

- Patients who were not prescribed any medication.

- Incomplete patient's medication chart and/or involuntary patients.

- Patients taking only topical agents.

\section{Sample size}

All available patients during the study period were taken and, therefore, total of 116 elderly populations were enrolled in the study. 


\section{Study variables \\ Independent variables: \\ - Age \\ - Sex \\ - Religion \\ - Occupation \\ - Marital status \\ - Social history \\ - Co-morbidities \\ - Diagnosis \\ - Medication category \\ - Number of drugs taken \\ Dependent variables: \\ - Poly-pharmacy}

\section{Data collection instrument and technique}

Instrument: The checklist/data collection format was adapted after reviews of different literatures. The format was further modified after a pre-test was conducted. The pre-test was done in SRH involving 20 patients with their medication card.

Data collection procedure: Data was collected by using pretested data collection format by two trained data collectors. Data on patient characteristics, diseases encountered and medications used was collected from the patient and his/her medication chart.

Data quality assurance: To assure the quality of the data, properly designed and pretested data collection checklist/questionnaire was used. Every day the collected data has been reviewed and checked for completeness and consistency.

\section{Data processing and analysis}

The collected data was analyzed by SPSS version 16.0 software. Descriptive statistics was used to describe the percentage and number distributions of variables in the study. Logistic regression analysis was used to assess the association between the independent variables with poly-pharmacy. The results were presented using tables, figures, percentages and texts as based on type of data.

\section{Ethical consideration}

First an official permission and formal letter was received from Ambo University, CMHS research and ethics committee and sent to $\mathrm{SRH}$. After relevant information was given on the research purpose and process, consent was given by patients or their attendants. Then the data collection was preceded accordingly by keeping privacy and confidentiality.

\section{Definition of terms}

Poly-pharmacy: Four or more medications taken concurrently.

Prescribing cascade: It is a condition when an adverse drug event is misinterpreted as a new medical condition and additional drug therapy is then prescribed to treat this medical condition.

Elderly: Peoples whose age is greater or equal to $65 \mathrm{yrs}$ old.
Co-morbidity: The presence of one or more diseases in addition to the primary diagnosis.

Primary diagnosis: Is the diagnosis for which the patient is either admitted or out patiently being treated with high attention while other diseases are taken as co-morbidity and can get their respective treatment.

Appropriate poly-pharmacy: Is when the patient is taking four or more drugs with appropriate indication, dose, frequency and duration of treatment.

Inappropriate poly-pharmacy: Is when at least one of the drugs, greater than or equal to four, the patient is taking is of inappropriate indication, dose, frequency and/or duration.

\section{Results}

\section{Socio-demographic characteristics of elderly patients}

The study involved 116 elderly (65 yrs and more) patients, who fulfilled inclusion criteria. Among these, more than half (59.5\%) were males whereas the majority of the total population $(62.9 \%)$ were $65 y$ rs to 69 yrs old. While the minimum age was 65 , the maximum was 95 yrs old. Similarly, $60.3 \%$ of them were married and farmer was the most frequently (38.8\%) reported occupation. Greater than two third $(87.1 \%)$ of total study population used coffee while $17.5 \%$ of study populations reported no use of any of alcohol, coffee, chat, drug of abuse and tobacco. Greater than half, 56\%, of the population was Muslim (Table 1).

\section{Clinical characteristics of elderly patients}

The primary diagnosis of most patients was infection. It contributes to $50 \%$ of all diseases and followed by CVD and endocrine disorders. Diabetes mellitus was the only disorder identified among endocrine disorders (Table 2).

Co-morbidity has been seen in almost one third of the study participants. While the minimum number of co-morbidity per those individuals with co-morbidity was one, the maximum was three comorbidities excluding the primary diagnoses (Figure 1).

In the same manner of the disease, the widely used drug group was antimicrobials, $58.7 \%$ and followed by cardiac drugs. Hypoglycaemic and GIT drugs were the second commonly used drug groups (Table 3 ).

The minimum total number of drugs the patient has been taking was one while the maximum was seven drugs of different classes. Almost half, (48.3\%), of populations were taking 1-2 drugs (Figure 2).

\section{Prevalence of poly-pharmacy}

Poly-pharmacy was incurred among almost one-third $(32.8 \%$, $\mathrm{n}=38$ ) of study subjects; $78.9 \%, \mathrm{n}=30$, of which being appropriate while the remaining $21.1 \%, \mathrm{n}=8$ was inappropriate poly-pharmacy (Figure 3).

The main cause of inappropriate poly-pharmacy was 'Unnecessary drug use', (75\%, $\mathrm{n}=6(\mathrm{~N}=8)$ ). 'High Dose' and 'High Duration of Treatment' have been observed equally to be the second cause of inappropriate poly-pharmacy, $(12.5 \%, \mathrm{n}=1(\mathrm{~N}=8))$ each (Figure 4$)$.

\section{Factors contributing to poly-pharmacy}

Analysis of association between all independent variables and poly-pharmacy was, first, done by Binary Logistic Regression. The 
Citation: Geresu GD, Yadesa TM, Abebe BA (2017) Polypharmacy and the Contributing Factors Among Elderly Patients in Shashemene Referral Hospital, West Arsi, Oromia Region, Ethiopia. J Bioanal Biomed 9: 277-282. doi:10.4172/1948-593X.1000193

\begin{tabular}{|c|c|c|c|c|}
\hline S. No. & \multicolumn{2}{|c|}{ Socio demography } & Frequency & Percent (\%) \\
\hline \multirow{5}{*}{1.} & \multirow{5}{*}{ Age in years } & $65-69$ & 73 & 62.9 \\
\hline & & $70-74$ & 24 & 20.7 \\
\hline & & $75-79$ & 9 & 7.8 \\
\hline & & $>1=80$ & 10 & 8.6 \\
\hline & & Total & 116 & 100 \\
\hline \multirow{3}{*}{2.} & \multirow{3}{*}{ Sex } & Male & 69 & 59.5 \\
\hline & & Female & 47 & 40.5 \\
\hline & & Total & 116 & 100 \\
\hline \multirow{5}{*}{3.} & \multirow{5}{*}{ Marital status } & Single & 6 & 5.2 \\
\hline & & Married & 70 & 60.3 \\
\hline & & Widowed & 31 & 26.7 \\
\hline & & Divorced & 9 & 7.8 \\
\hline & & Total & 116 & 100 \\
\hline \multirow{6}{*}{4.} & \multirow{6}{*}{ Social history } & Alcohol & 24 & 20.7 \\
\hline & & Tobacco & 2 & 1.7 \\
\hline & & Chat & 8 & 6.9 \\
\hline & & Coffee & 101 & 87.1 \\
\hline & & None & 6 & 5.2 \\
\hline & & Total & 141 & 121.6 \\
\hline \multirow{6}{*}{5.} & \multirow{5}{*}{ Occupation } & Employee & 10 & 8.6 \\
\hline & & Farmer & 45 & 38.8 \\
\hline & & Housewife & 21 & 18.1 \\
\hline & & Retiree & 3 & 2.6 \\
\hline & & Unemployed & 37 & 31.9 \\
\hline & & Total & 116 & 100 \\
\hline \multirow{5}{*}{6.} & \multirow{5}{*}{ Religion } & Orthodox & 29 & 25 \\
\hline & & Protestant & 16 & 13.8 \\
\hline & & Catholic & 6 & 5.2 \\
\hline & & Muslim & 65 & 56 \\
\hline & & Total & 116 & 100 \\
\hline
\end{tabular}

Table 1: The socio-demographic data of elderly patients at SRH from March up to April, 2017.

\begin{tabular}{|c|c|c|c|}
\hline S. NO. & Disease & Frequency & Percent (\%) \\
\hline 1. & Infection & 58 & 50 \\
\hline 2. & CVD & 21 & 18.1 \\
\hline 3. & Endocrine disorders & 20 & 17.2 \\
\hline 4. & GIT & 9 & 7.8 \\
\hline 5. & CNS disorders & 8 & 6.9 \\
\hline 6. & Urologic disorders & 5 & 4.3 \\
\hline 7. & Respiratory disorders & 3 & 2.6 \\
\hline 8. & Hematologic disorders & 1 & 0.9 \\
\hline & Total & 125 & 107.8 \\
\hline
\end{tabular}

Table 2: Clinical characteristics of the study subjects at SRH from March up to April, 2017.

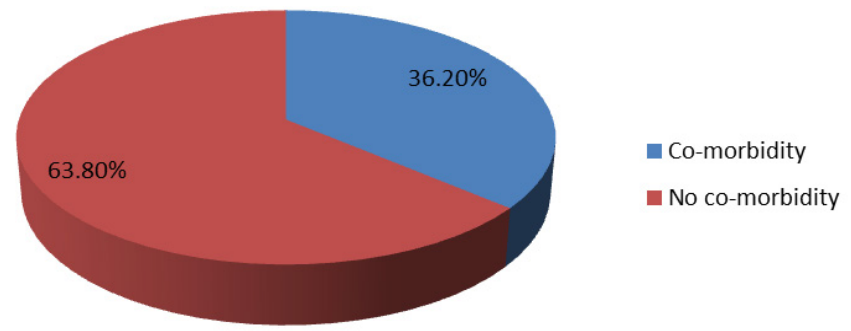

Figure 1: Co-morbidity among the study participants at SRH from March up to April, 2017.

\begin{tabular}{|c|c|c|c|}
\hline S.NO. & Drugs & Frequency (n) & Percent (\%) \\
\hline 1. & Antimicrobial drugs & 68 & 58.7 \\
\hline 2. & Cardiovascular drugs & 29 & 25 \\
\hline 3. & GIT drugs & 16 & 13.8 \\
\hline 4. & Hypoglycemic drugs & 16 & 13.8 \\
\hline 5. & CNS drugs & 12 & 10.3 \\
\hline 6 & Hementics & 3 & 2.6 \\
\hline 7. & Respiratory drugs & 2 & 1.8 \\
\hline 8. & Anti-inflammatory drugs & 1 & 0.9 \\
\hline
\end{tabular}

Table 3: Drugs used by elderly patients at SRH from March up to April, 2017.

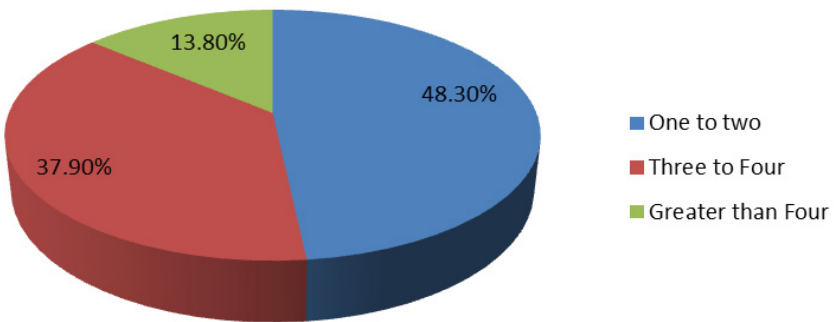

Figure 2: Number of drugs per elderly patients at SRH from March up to April, 2017.

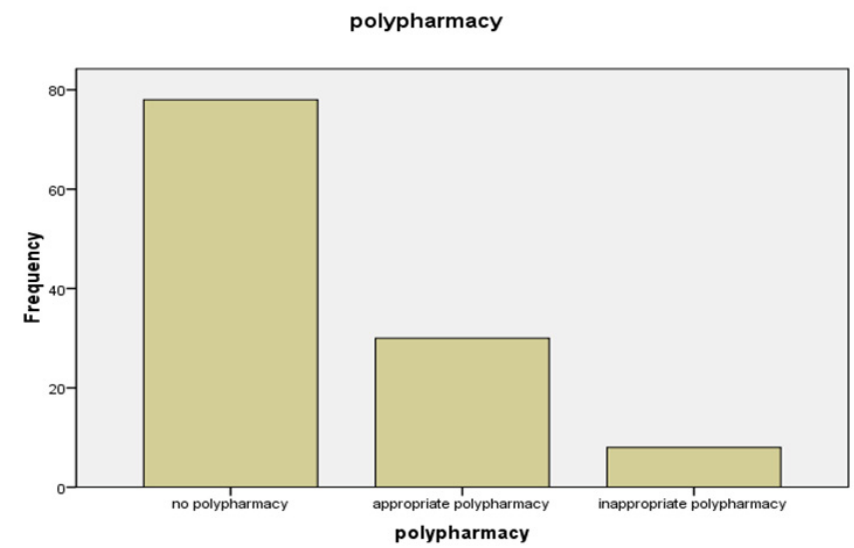

Figure 3: Types of observed poly-pharmacy among elderly patients at $\mathrm{SRH}$ from March up to April, 2017.

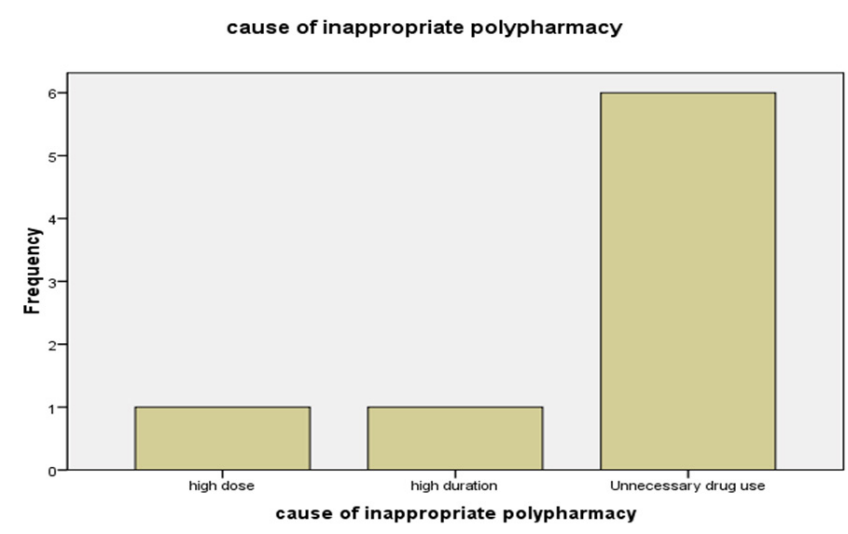

Figure 4: Causes of observed inappropriate poly-pharmacy among elderly patients at SRH from March up to April, 2017. 
Citation: Geresu GD, Yadesa TM, Abebe BA (2017) Polypharmacy and the Contributing Factors Among Elderly Patients in Shashemene Referral Hospital, West Arsi, Oromia Region, Ethiopia. J Bioanal Biomed 9: 277-282. doi:10.4172/1948-593X.1000193

\begin{tabular}{|c|c|c|c|c|c|c|c|c|}
\hline \multirow{2}{*}{ S.NO. } & \multirow{2}{*}{ Variables } & \multirow{2}{*}{ Categories } & \multicolumn{6}{|c|}{ Poly-pharmacy } \\
\hline & & & Yes & No & $\operatorname{COR}[95 \% \mathrm{Cl}]$ & P-value & AOR $[95 \% \mathrm{Cl}]$ & P-value \\
\hline \multirow{2}{*}{1.} & \multirow{2}{*}{ Sex } & Male & 19 & 50 & $0.560[0.255-1.229]$ & 0.148 & $0.511[0.154-1.693]$ & 0.272 \\
\hline & & Female & 19 & 28 & 1 & & & \\
\hline \multirow{4}{*}{2.} & \multirow{4}{*}{ Age } & $65-69$ & 24 & 49 & 1 & & & \\
\hline & & $70-74$ & 9 & 15 & 1.959 [0.386-9.946] & 0.417 & $2.851[0.736-11.046]$ & 0.130 \\
\hline & & $75-79$ & 3 & 6 & $2.400[0.415-13.895]$ & 0.329 & $0.482[0.077-3.013]$ & 0.435 \\
\hline & & $>/=80$ & 2 & 8 & $2.00[0.250-15.991]$ & 0.513 & $0.243[0.028-2.149]$ & 0.204 \\
\hline \multirow{8}{*}{3.} & \multirow{8}{*}{ Disease } & CNS disorders & 0 & 8 & 0.000 & 0.999 & $0.000[0.000-E]$ & 0.999 \\
\hline & & CVD & 11 & 10 & $4.400[0.418-46.261]$ & 0.217 & $3.899[0.261-58.320]$ & 3.324 \\
\hline & & Endocrine disorders & 1 & 15 & $0.267[0.014-5.267]$ & 0.385 & $0.098[0.003-3.181]$ & 0.191 \\
\hline & & GIT disorders & 3 & 6 & $2.000[0.150-26.734]$ & 0.600 & $1.137[0.054-24.137]$ & 0.935 \\
\hline & & Hematologic disorders & 1 & 6 & ---- & 1.000 & 1.348E10[0.000-E] & 1.000 \\
\hline & & Infection diseases & 20 & 33 & $2.424[0.253-23.246]$ & 0.443 & $2.369[0.172-32.620]$ & 0.519 \\
\hline & & Respiratory diseases & 1 & 2 & 2 [0.078-51.593] & 0.676 & $0.646[0.019-21.964]$ & 0.808 \\
\hline & & Urologic disorders & 1 & 4 & 1 & & & \\
\hline \multirow{2}{*}{4.} & \multirow{2}{*}{ Co-morbidity } & Yes & 24 & 18 & 5.714 [2.458-13.286] & 0.000 & $7.427[2.511-21.973]$ & 0.000 \\
\hline & & No & 14 & 60 & 1 & & & \\
\hline \multirow{4}{*}{5.} & \multirow{4}{*}{ Marital status } & Single & 1 & 5 & $0.100[0.008-0.1 .288]$ & 0.077 & $0.274[0.010-7.880]$ & 0.450 \\
\hline & & Married & 20 & 50 & $0.200[0.046-0.878]$ & 0.033 & $0.133[0.014-1.274]$ & 0.080 \\
\hline & & Widowed & 11 & 20 & $0.275[0.057-1.321]$ & 0.107 & $0.160[0.015-1.721]$ & 0.131 \\
\hline & & Divorced & 6 & 3 & 1 & & & \\
\hline \multirow{5}{*}{6.} & \multirow{5}{*}{ Occupation } & Employee & 7 & 3 & $3.422[0.761-15.388]$ & 0.109 & $8.840[1.122-69.676]$ & 0.039 \\
\hline & & Farmer & 8 & 37 & 0.317 [0.116-0.868] & 0.025 & $0.419[0.127-1.381]$ & 0.153 \\
\hline & & House wife & 7 & 14 & $0.733[0.239-2.247]$ & 0.587 & $0.828[0.192-3.573]$ & 0.801 \\
\hline & & Retiree & 1 & 2 & 0.733 [0.001-8.832] & 0.807 & $1.225[0.090-16.597]$ & 0.879 \\
\hline & & Unemployed & 15 & 22 & 1 & & & \\
\hline \multirow{4}{*}{7.} & \multirow{4}{*}{ Religion } & Orthodox & 11 & 18 & $1.725[0.679-4.382]$ & 0.251 & $0.871[0.183-4.152]$ & 0.862 \\
\hline & & Protestant & 7 & 9 & 2.196 [0.708-6.812] & 0.173 & $2.396[0.447-12.855]]$ & 0.308 \\
\hline & & Catholic & 3 & 3 & $2.824[0.519-15.351]$ & 0.230 & $0.729[0.051-10.494]$ & 0.816 \\
\hline & & Muslim & 17 & 48 & 1 & & & \\
\hline
\end{tabular}

Table 4: The Contributing factors of poly-pharmacy among elderly patients at SRH from March up to April, 2017.

binary logistic regression showed that marital status [married] with $(\mathrm{COR}=0.200[0.046-0.878] ; \mathrm{p}$ value $=0.033$ at $95 \% \mathrm{CI})$, comorbidity with $(\mathrm{COR}=5.714$ [2.458-13.286]; $\mathrm{p}$ value $=0.000$ at $95 \%$ $\mathrm{CI})$ and occupation [Farmer] with $(\mathrm{COR}=0.317$ [0.116-0.868]; p-value $=0.025)$ were significantly associated with poly-pharmacy. Age and social history were excluded from multivariate logistic regression because of $\mathrm{p}$ values were greater than 0.25 . However, the multivariate logistic regression showed that only co-morbidity [AOR=7.427 [2.511-21.973] at 95\% CI, $\mathrm{P}=0.000]$ and occupation, employed, $[\mathrm{AOR}=8.840[1.122-69.676]$ at $95 \% \mathrm{CI}, \mathrm{P}=0.039$ ] regained their significant association. Accordingly, patients with at least one co-morbidity were about 7.427 [AOR=7.427 [2.51121.973] at $95 \% \mathrm{CI}, \mathrm{P}=0.000$ ] times more likely to experience polypharmacy compared to those with no co-morbidities. Similarly, among occupation those patients who are employed were about 8.840 [AOR=8.840[1.122-69.676] at 95\% CI, $\mathrm{P}=0.039]$ times more likely to be on poly-pharmacy than those who are unemployed.

\section{Discussion}

According to this study poly-pharmacy has been defined as concomitant use of four or more prescription drugs and/or administration of more medications than clinically indicated, representing unnecessary drug use. Further, observed poly-pharmacy has been classified in to appropriate and inappropriate poly-pharmacy by using Ethiopian Standard Treatment Guideline, 2014 as a reference. Indication, drug dose, frequency and duration of treatment have been compared with the guideline to determine the type of observed polypharmacy as either appropriate or inappropriate.

In this study, a total of 116 elderly patients, 69 males and 47 females, were involved. The most frequently identified (50\%) primary diagnosis was infection; followed by CVD 21(18.1\%). This is comparable with the study done in Ayder referral hospital, Tigray, Ethiopia which showed that infection diseases were diagnosed in $58.6 \%$ of the study participant [20]. However according to the retrospective study done in Oman [6], more patients had CVD on admission (31\%) followed by infection (23.0\%) and GIT diseases (13\%). This might be consistent with the possible reason that CVD are highly prevalent among higher income countries while infection is common among developing countries including Ethiopia.

Co-morbidity has been seen in over one-third (36.2\%) of the study subjects. This is similar with the result of study done in Ayder referral hospital, Tigray, Ethiopia, in which $38 \%$ of the participants had comorbid conditions [19].

The most widely used drug group was antimicrobials, 58.7\%, followed by cardiovascular drugs $(25 \%)$. In contrast to the WHO recommendation, over half $(51.7 \%)$ of the participants used more than two drugs [20].

The present study shows that the prevalence of poly-pharmacy is $32.8 \%$ among elderly in SRH. This much is lower than $82 \%$ of retrospective observational study done in King Fahad Cardiac Center 
Citation: Geresu GD, Yadesa TM, Abebe BA (2017) Polypharmacy and the Contributing Factors Among Elderly Patients in Shashemene Referral Hospital, West Arsi, Oromia Region, Ethiopia. J Bioanal Biomed 9: 277-282. doi:10.4172/1948-593X.1000193

(KFCC) [5] and 52.2\% in a study in Zambia [21]. On the other hand the prevalence of poly-pharmacy was higher compared to only $8 \%$ in Belgium [22]. This might be due to availability of technology and facility in developed countries to keep the patients' medication to minimum effective and safe number of drugs.

From the total of 38 incidences of poly-pharmacy, most $(78.9 \%, \mathrm{n}=30$, were appropriate while the remaining $8(21.1 \%)$ was inappropriate poly-pharmacy. This is comparable with a study from Gondar, Ethiopia, in which $27.72 \%$ of the elderly patients' experienced inappropriate poly-pharmacy [23]. On the other hand, only $21.1 \%$ of the poly-pharmacy was identified to be inappropriate type in this study as compared to $87.5 \%$ in a study conducted in India [24]. This higher prevalence of appropriate poly-pharmacy in current study may be due to the higher prevalence chronic infections, particularly HIV/AIDS and tuberculosis, thereby contributing for more number of drugs indicated.

This study showed that no association was found between age and gender with poly-pharmacy. Similarly the study done in Oman showed that no association was detected between poly-pharmacy and age as well as gender.

On the other hand, the multivariate logistic regression showed that co-morbidity $[\mathrm{AOR}=7.427[2.511-21.973]$ at $95 \% \mathrm{CI}, \mathrm{P}=0.000]$ and occupation, employed, $[\mathrm{AOR}=8.840[1.122-69.676]$ at $95 \% \mathrm{CI}$, $\mathrm{P}=0.039$ ] were independent factors that were significantly associated with poly-pharmacy. Similarly, the study done in Karnataka, India [24] showed that co-morbid condition was the major risk factor of polypharmacy. This is rational because the more numbers of co morbidities, the higher number of drugs prescribed. For the occupation [Employed] as independent predictor of poly-pharmacy, the fact that the employed patients might have significantly different living style may contribute for variation of prevalence of different diseases like cardiovascular diseases and thus, more poly-pharmacy prevalence.

\section{Conclusion and Recommendation}

\section{Conclusion}

In this study, a total of 116 elderly patients, 69 males and 47 females, were involved. Co-morbidity has been seen in over one-third of the study subjects. The study also shows that poly-pharmacy was prevalent in almost one third of the elderly patients in SRH. The multivariate logistic regression showed that co-morbidity and occupation were the factors independently associated with poly-pharmacy.

\section{Recommendation}

By considering the finding of the study we would like to recommend that even though the majority of observed poly-pharmacy was appropriate, the health care system should improve the prescribing process among elderly patients in general and those with additional co-morbidities in more emphasis. Moreover, the hospital and all the health professionals in the hospital should cooperate in educating the elderly patients, particularly those with co-morbidity on the rational use of their medicines and adhering to healthy life styles. Regular medication chart review is required among health care professionals to avoid DRP in elderly patients.

\section{Acknowledgements}

We would like to acknowledge administrative workers and health professionals of Shashemene referral hospital for their cooperation during the data collection.

\section{Funding}

No fund was obtained.

\section{Competing Interests}

The authors declare there is no competing interest.

\section{References}

1. Lokender $P$ (2015) Prevalence and risk factors of poly-pharmacy among elderly in India: Evidence from SAGE Data. Int J Public Ment Health Neurosci 2: 11-14.

2. Fantahun M, Berhane $Y$, Högberg U, Wall S, Byass $P$ (2009) Aging of a rura Ethiopian population: Who are the survivors? Public Health 123: 326-330.

3. Cadogan CA, Ryan C, Hughes CM (2016) Appropriate poly-pharmacy and medicine safety: When many is not too many. Drug Saf 39: 109-116.

4. Mahler RL, Hanlon JT, Emily R, Hajjar ER (2014) Clinical consequences of poly-pharmacy in elderly. Expert Opin Drug Saf 13: 57-65.

5. Syed Wajid (2014) Prevalence of Poly-pharmacy in elderly cardiac patients at King Fahad Cardiac Center (KFCC) in King Khalid University Hospital (KKUH), Riyadh, Saudi Arabia. Int J Recent Sci Res 5: 1053-1057.

6. Al-Hashar A, Al Sinawi H, Al Mahrizi A, Al-Hatrushi M (2016) Prevalence and covariates of poly-pharmacy in elderly patients on discharge from Tertiary Care Hospital, Oman. Oman Med J 31: 421-425.

7. Stewart RB (1990) Polypharmacy in the elderly: A fait accompli? DICP 24: 321 323

8. Montamat SC, Cusack B (1992) Overcoming problems with polypharmacy and drug misuse in the elderly. Clin Geriatr Med 8: 143-158.

9. Rambhade S, Chakarborty A, Shrivastava A, Patil UK, Rambhade A (2012) A Survey on Poly-Pharmacy and Use of Inappropriate Medication. Toxicol Int 19: $68-73$

10. Abdulraheem IS (2013) Poly-pharmacy: A risk factor for geriatric syndrome multi morbidity and mortality. Aging Sci 1: e103.

11. Alpana Mair (2015) Poly-pharmacy Guidance. $1^{\text {st }}$ edn. Scottish Government Scotland.

12. Patterson SM, Hughes C, Kerse N, Cardwell CR, Bradley MC (2012) Interventions to improve the appropriate use of polypharmacy for older people. Cochrane Database Syst Rev.

13. Hajjar ER1, Cafiero AC, Hanlon JT (2007) Poly-pharmacy in elderly patients Am J Geriatr Pharmacother 5: 345-351.

14. Salwe KJ, Kalyansundaram D, Bahurupi Y (2016) A Study on poly-pharmacy and potential drug-drug Interactions among elderly patients admitted in Department of Medicine of a Tertiary Care Hospital in Puducherry. J Clin Diagn Res 10: Fc06-Fc10.

15. Zagaria MAE (2006) Poly-Pharmacy and Potentially Inappropriate Medication in the Elderly Across the Practice-Setting Spectrum. 10: 112-116.

16. http://www.worldometers.info/world-population/ethiopia-population/

17. Ayalew MB, Megersa TN, Mengistu YT (2015) Drug- related problems in medical wards of Tikur Anbessa specialized hospital, Ethiopia. J Res Pharm Pract 4: 216-221.

18. http://www.columbia.edu/itc/hs/medical/clerkships/primcare/case/ hypertension/library/Polypharmacy.pdf

19. Teka F, Teklay G, Ayalew E, Teshome T (2016) Potential drug-drug interactions among elderly patients admitted to medical ward of Ayder Referral Hospital, Northern Ethiopia: A cross sectional study. BMC Res Notes 9: 431.

20. Holloway K, Dijk LV (2011) Rational use of medicines. The world medicines situation, $3^{\text {rd }}$ edn Geneva: WHO.

21. Lukali V, Michelo C (2015) Factors Associated with irrational drug use at distric use in Zambia: Patient record based observations. Med J Zambia 41: 25-30.

22. Walckiers D, Van der Heyden J, Tafforeau J (2015) Factors associated with excessive poly-pharmacy in older people. Arch Public Health 73: 50.

23. Mekonen AB, Bhagavathula AS (2014) Inappropriate medication use in the elderly population attending Gondar University Hospital. IJPPS 6.

24. Tamang, Basafaraj K Nanjwade (2016) A prospective surveillance study of poly-pharmacy in Geriatrics. Implication of age, gender, risk factors and drug interactions. WJPPS 5: 1451-1466. 